\title{
IMMEDIATE FEVER AFTER CLEAN OPERATIONS (CLASS I OF ALTEMEIER) IN THE NORTHEAST OF THE DEMOCRATIC REPUBLIC OF THECONGO (DRC): ETIOLOGIC AND THERAPEUTIC ASPECTS
}

\section{MaoneoAzabali*., TalonaLehumadja., AwikokoMutupeni., Mukulutaghe Pierre and AhukaonaLongombe}

\author{
Department of Surgery, Faculty of Medicine, University of Kisangani Democratic Republic of the Congo
}

DOI: http://dx.doi.org/10.24327/ijrsr.2017.0805.0224

\section{ARTICLE INFO}

\section{Article History:}

Received $10^{\text {th }}$ February, 2017

Received in revised form $14^{\text {th }}$

March, 2017

Accepted $08^{\text {th }}$ April, 2017

Published online $28^{\text {th }}$ May, 2017

Key Words:

Postoperative fever, postoperative infection, postoperative malaria.

\begin{abstract}
Background: A high temperature compared to normal in postoperative first forty-eight hours or immediate postoperative fever is commonly observed and raises anxiety both in the patient than in the caregiver himself. This last is still in trouble whether the fever is related or no to infection especially when the operation is clean. This study aims to determine association between the immediate postoperative fever and infection after clean operations (Class I of Althemeir) in order to limit the misuse of antibiotics and antimalarials.

Patients and Methods: This is a prospective study led at the Referral General Hospital of Kabondo, in the city of Kisangani to north-eastern of Democratic Republic of Congo, with 209 operated. Data were recorded on Excel spreadsheet and analyzed with SPSS 20 software.

Results: In the immediate postoperative period, 29 (13.87\%) operated presented fever. $51.72 \%$ of these fevers were moderate around $38^{\circ} \mathrm{C}$ to $39^{\circ} \mathrm{C}$. Caesareans predominated $(48.27 \%)$. The systemic inflammatory syndrome was found in $55.17 \%$ of the cases followed of the malaria in $41.38 \%$ of which $37.93 \%$ with the positive thick drop. All operated were under a post-operative systematic antibiotherapy $(100 \%)$ and $55.17 \%$ of operated received association antibiotics, antipyretics and antimalarials.

Conclusion: Most of immediate post-operative fever after a clean operation is not infectious although malaria remains as significant cause in countries with malaria endemicity.
\end{abstract}

Copyright (C) MaoneoAzabali et al, 2017, this is an open-access article distributed under the terms of the Creative Commons Attribution License, which permits unrestricted use, distribution and reproduction in any medium, provided the original work is properly cited.

\section{INTRODUCTION}

A high temperature compared to normal in postoperative first forty-eight hours or immediate postoperative fever is common observation. It found, according to the studies series, at 12.8 to $50 \%$ of the operated $[1,2]$. The problem is to know if this immediate post-operative fever is relative or no to an infection. For Ballestas, immediate postoperative fever is non-infectious. It is a normal inflammatory response of the organism to surgical aggression [3] mediated by Interleukin 6 [4]

But the situation presents itself otherwise in the regions where rage of the endemic febrile pathologies. Post-operative fever is often attached to a preoperative infectious cause for which expression would be favored by the surgical trauma. Then several therapeutic attitudes have emerged.

Some authors recommend in the regions like ours a systematic treatment of the endemic febrile affections such the malaria, considered empirically as potential reasons of the immediate post-operative fever [5]. Pile speaks of a blind mass treatment with antimalarials and the antibiotics like a "shotgun" [6]. Other researchers such as Diako, Van, bib, Gazin, much more moderate, require hand in-depth investigations before starting any specific anti-infective treatment [7]. Finally other authors, as Xie, Luo and Xue, proceed by the antibioprophylaxy, but the results do not give a significant difference compared to the non-recipient operated [8]. All of these therapeutic attitudes have a consequent cost [9]. This study aims to determine association between the immediate postoperative fever and infection after clean operations (Class I of Althemeir) in order to limit the misuse of antibiotics and antimalarials.

\section{PATIENTS AND METHODS}

We conducted a prospective cross-sectional study at the Referral General Hospital (RGH) of Kabondo, in the city of Kisangani situated at the North-East of the DRC (Democratic Republic of Congo) from July $1^{\text {st }}$ to December $31^{\text {th }}, 2015$. The hospital was of secondary level, located at the East of the city of Kisangani, with a capacity of 150 beds. The medical staff

*Corresponding author: MaoneoAzabali

Department of Surgery, Faculty of Medicine, University of Kisangani Democratic Republic of the Congo 
counted 2 residents physicians and 7 internal physicians.

The study population has been constituted of all patients who had clean operations to the departments of surgery and obstetrics gynecologist during the period of study. We recorded 209 cases. Among these operated, 29 presented the fever in the forty eight first post-operative hours and constituted our study sample. The average age was of 29.4 years with extremes of 13 and 72 .

\section{Inclusion criteria}

All patients who received a surgical management of class I of Altemeierat the RGH of Kabondo in the period of study and at which there was a febrile episode during the first 48 postoperative hours.

\section{Exclusion criteria}

- All operated whom fever has begun before the surgery. Postoperative fever might be that the continuity of the pre-operative episode.

- Patient with a septic condition proved as acute generalized peritonitis, wounds or infected fractures...

- Pregnant patient with rupture of membranes.

- In these two cases the intervention is contaminated and the link between the immediate postoperative fever and infection is obvious, antibiotic use is justified.

- Patient medication: tuberculosis drugs, cancer drugs, corticosteroids, diabetes drugs... Indeed, the above drugs are likely to induce fever immediate in postoperative period.

\section{Data collection technique}

We have done the following way: the first day on the seventh post-operative day, clinical parameters have been evaluated at all the class I of Altemeier operated.

Operated with fever during the first two days have been monitored closely as well as those whose fever continued until the third day and whose curve showed no trend downward. Clinics data, para clinics (thick drop, rapid test of malaria, the speed of sedimentation (VS), (Hb), count white blood cells (GB), the formula leukocyte (FL), the WIDAL, the antibodies to HIV AIDS research) and treatment have been recorded either by ourselves or by two members of the hospital.

As treatment, during the first two postoperative days, in addition to the already established antibiotics, we administered only antipyretics. If fever dropped the same day or in the evening of the second day without ever appearing in the following days with decline in the sedimentation rate, fever was attributed to the response of the body against surgical aggression or systemic inflammatory syndrome. In case of persistence of fever beyond third day, we asked reviews thick gout, rapid test of malaria and WIDAL. We give the same malaria if the results of thick gout or rapid test of malaria were negative. Musicif fever after taking these anti-malarial drugs, we thought then to a malarial origin.

We considered:

\section{Improvement}

- Any patient whose fever dropped after taking antipyretics in the first two days with drop speed of sedimentation in the case of inflammatory syndrome systemic.

- Any patient whose fever went down after the administration of a drug in case of persistence of fever beyond the second day.

\section{Stationary case}

Any patient whose fever was maintained despite the antibiotics, antipyretics and the anti-malarial drugs. Also note that all operated were subjected systematically to antibiotics to minimize the hypothesis of an infectious origin in case of immediate postoperative fever.

The classification of the wounds was made according to Altemeir (10):

We have included in the own wounds, not strangled hernia, uninfected bone interventions, Caesarean sections on a uterus with no broken water, intestinal occlusions on flange or grip without opening of the viscera.

Then, the quantification of fever was made as follows:

- Low-grade fever: $37.5^{\circ} \mathrm{C}-37.9^{\circ} \mathrm{C}$

- Moderate fever: $38.0^{\circ} \mathrm{C}-39.0^{\circ} \mathrm{C}$

- High fever: $39.1^{\circ} \mathrm{C}-40.0^{\circ} \mathrm{C}$

- Malignant fever: more than $40^{\circ} \mathrm{C}$

The data collected were recorded on an Excel spreadsheet and analysed using the software SPSS 20.

\section{RESULTS}

\section{Prevalence}

On 209 operated 29 (13. 87\%) cases presented an immediate post-operative fever.

\section{Socio-demographic characteristics of the patients}

Among the 29 patients 10 (34.48\%) were men and 19 (65.51\%) women. Their ages range from 13 to $72 \mathrm{~s}$ with the average age of 29, 4 years. The most represented age group was between 23 and 32 years in $41.37 \%$. The majority of these $(48,27 \%)$ operated from the town ship of Kabon do (table I).

Table I socio-demographic characteristics of the patients

\begin{tabular}{ccc}
\hline $\begin{array}{c}\text { Socio-demographic characteristics of the } \\
\text { patients }\end{array}$ & $\mathbf{n}$ & $\mathbf{\%}$ \\
\hline Sex & 19 & 65.52 \\
Feminine & 10 & 34.48 \\
Masculine & & \\
Age group (years) & 5 & 17.24 \\
$13-22$ & 12 & 41.37 \\
$23-32$ & 8 & 27.58 \\
$33-42$ & 1 & 3.45 \\
$43-52$ & 1 & 3.45 \\
$53-62$ & 2 & 6.89 \\
63-72 & & \\
Residential township & 14 & 48.27 \\
Kabondo & 6 & 20.68 \\
Kisangani & 2 & 6.89 \\
Makiso & 1 & 3.45 \\
Tshopo & 1 & 3.45 \\
Lubunga & 5 & 17.24 \\
\hline Periphery & & \\
\hline
\end{tabular}




\section{Operative indications}

The Caesareans constituted the major operative indication in this study with $48.27 \%$ (Table II)

Table II Operative indications

\begin{tabular}{lcc}
\hline \multicolumn{1}{c}{ Operative indications } & $\mathbf{n}$ & $\mathbf{\%}$ \\
\hline$\quad \begin{array}{l}\text { Caesarean } \\
\text { Interventions on the bone }\end{array}$ & 14 & 48.27 \\
- $\quad \begin{array}{c}\text { Fracture communitive of two bones of the left } \\
\text { leg }\end{array}$ & 3 & 10.34 \\
- Fracture left middle-patellaire & 2 & 6.89 \\
- Vicious callus on fracture of the left thighbone & 1 & 3.45 \\
- Fracture of the right femoral diaphyse & 1 & 3.45 \\
$\quad$ AIO (Acute intestinal occlusion) & 6 & 20.69 \\
$\quad$ Hernia & 2 & 6.89 \\
\hline
\end{tabular}

\section{Characteristics of the fever}

The majority $(51.72 \%)$ of our patients had a fever curbed between $38,0^{\circ} \mathrm{C}$ to $38.9^{\circ} \mathrm{C}$. This one was a lot more due to the inflammatory reaction syndrome $(51.72 \%)$ follow-up of the malaria $(37.93 \%)$ with $37.67 \%$ of positive thick drop (Table III).

Table III Characteristics of the fever

\begin{tabular}{ccc}
\hline Characteristics of the fever & n & \% \\
\hline Quantification in ${ }^{\circ} \mathbf{C}$ & 1 & 3.45 \\
$37,5-37,9$ & 15 & 51.72 \\
$38,0-38,9$ & 11 & 37.94 \\
$39,0-39,9$ & 2 & 6.89 \\
$\geq 40$ & & \\
Etiology & 15 & 51.72 \\
SystemicInflammatory Syndrome (SIS) & 11 & 37.94 \\
$\quad$ Malaria & 3 & 10.34 \\
\hline Unknownreasons & &
\end{tabular}

\section{Paraelinie, treatment and evolution}

The thick drop was done at 19 operated and 10 other patients didn't benefit some. On the 19 exams of thick drop done, 11 $(57.9 \%)$ were positive and $8(42.1 \%)$ negative. A lot of operated $(55.17 \%)$ received the association of antibiotic, antimalarial and antipyretic while all (100\%) benefitted some antibiotics. After treatment, the fever lowered at $89.5 \%$ of our operated (Table IV).

Table IV Thick drop, treatment of the fever and evolution after treatment

\begin{tabular}{|c|c|c|c|c|c|}
\hline $\begin{array}{l}\text { Drop } \\
\text { Thick }\end{array}$ & $\begin{array}{l}\text { Frequency } \\
(\%)\end{array}$ & Treatment of thefever & $\begin{array}{c}\text { Frequency } \\
(\%)\end{array}$ & Evolution & $\begin{array}{c}\text { Frequency } \\
(\%)\end{array}$ \\
\hline Positive & $11(37.94)$ & $\begin{array}{c}\text { Antibiotic+antipyretic }+ \\
\text { antimalarial }\end{array}$ & $12(41.38)$ & mprovment & $26(89.66)$ \\
\hline Negative & $8(27.58)$ & Antibiotic+antipyretic & $16(55.17)$ & $\begin{array}{l}\text { Stational } \\
\text { state }\end{array}$ & $2(6.89)$ \\
\hline Nonrated & $10(34.48)$ & Antibiotic+antipyretic & $1(3.45)$ & Death & $1(3.45)$ \\
\hline
\end{tabular}

\section{DISCUSSION}

\section{Prevalence of immediate postoperative fever}

The prevalence of immediate postoperative fever $(13.87 \%)$ obtained in this work is almost the same as that of Nelson, Mugisa, Watya (13.7\%) [11] and it is slightly higher than that of Bozkurt, Yumru, Salman (12.8\%) [2]. Athanassious, Samad, Avery, Cohen, Chalnick [12] and [1] Perlino found heads far superior to ours of the order of $40 \%$ to $50 \%$.

The difference could be explained by the diversity of our study circles, of the size of the sample, and the types of services and support in postoperative immediate Protocol.
Moreover, immediate postoperative fever is the field function, the length and especially the type of interventions. The exclusion of some potentially febrile patients in our sample would have affected significantly the prevalence.

The prevalence of immediate postoperative fever in patients aged 23 and 32 (41.37\%) and mainly women could translate the composition of our sample. There has been many cases of caesarean section. This observation was also made by Longombe and Ukumu [13] in their study on post-operative malaria.

We believe that it is the age of procreation by excellence. In addition, except Caesarean sections, the data of other surgical pathologies are variously interpreted between the two sexes.

The residence doesn't have an impact on the occurrence of the immediate postoperative fever, high frequency of cases in the commune $\mathrm{k}(48.27 \%)$ is based on the proximity of this common compared to the HGR Kabondo.

\section{Fever Characteristics}

The most frequent causes of immediate post-operative fever at the general hospital of $\mathrm{k}$ are systemic inflammatory syndrome $(55.17 \%)$ and malaria $(41.38 \%)$. It is in most cases of moderate or mild fever around $38 \mathrm{oC}$ to $39 \mathrm{oC}$ and which falls at the end of the second day as stated Perlino [1] and Uckay, Agostinho, Stern, et al [14].

Ohanaka and Evbuomwa [5] got 36, 6\%; Than, Malovics, (87\%) [15] the non-infectious causes of immediate postoperative fever; values that are similar to ours. ADF Alla, Alhal, Ahmed, hassan and Pattem found, in a similar study, the same causes but with different proportions of ours. For them the indeterminate infections come to mind with $14,6 \%$ followed malaria 9.6\% [16]. Perlino [1] and Fanning, Brewer, (84\%) [17] place in mind the causes unknown but considered to be non-infectious in the event of immediate postoperative fever.

In spite these different results, it is clear that unknown causes identified by the above authors could simply be summed up in the response of the body against surgical stress what we called " systemic inflammatory syndrome. " The body reacts against the stitches, the bleeding or hematoma, products administered including antipyretics and anesthetics [18]. He reacts against certain types of surgery: tonsillectomy or tonsillectomie in children, surgery in the elderly, gynecological surgery, cardiovascular, major abdominal surgeries or traumaorthopedic surgeries $[1,18]$.

Malaria remains a significant cause of immediate postoperative fever as reported by Longombe and Ukumu (28\%) [12], Tai, Chang, Lin, Lai, Yang [19] (30\%). Postoperative trauma can be responsible for physiological imbalance thus allowing latent malaria take over the immune system and manifest clinically in immediate post-operative. Malaria must be actively searched [11].

\section{Treatment}

The systematic administration of antibiotics to the (100\%) operated in our work was introduced to minimize the infectious origin of the fever. Furthermore, this practice is particularly observed in several countries in developing such as ours where 
working conditions are precarious in order to prevent infection. Nelson, Ntakiyiruta G, Mugisa BD Watya SG. (2006), Mugisa and Watya found the prescription of antibiotics in postoperative at Mulago Hospital in Uganda in $93.5 \%$ of the operated 5 days [11].

\section{CONCLUSION}

The immediate postoperative fever is not significantly associated with infection at the Reference General Hospital of Kabondo in patients who have had own interventions. Systemic inflammatory syndrome due to surgical stress is found in the majority of monitoring cases of malaria.

\section{References}

1. Perlino T. (2001): Postoperative fever. Med Wink North Am, 85 (5):1141-9.

2. Bozkurt M, Yumru AE, Salman S. (2015): Assessment of perioperative, early, and late postoperative complications of the inside-out transobturator hits procedure in the treatment of stress urinary incontinence Wink ExpObstet Gynecol,42(1):82-9

3. Ballestas HC. (2007): Postoperative fever: to what is the leotard really responding? AORN J; 86(6):983-8;

4. André AM, and al. (2003): Postoperative fever after total knee arthroplasty: the role of cytokines. ClinOrthopRelat Res; 415:221.

5. Ohanaka EC, Evbuomwan I. (2003): Confirmation of malaria parasitaemia and management of postoperative pyrexia. Nigerian Newspaper of Surgical Research; 5 (1): 62-6.

6. BatteryJC. (2006): Evaluating postoperative fever: has focused approach. Cleve Wink J Med; 73:62-66. doi: 10.3949/ccjm.73.Suppl 1.S62.

7. Diako P, Van J, Bonkoungou B, Gazin P. (1994): The malaria in the continuations of the surgical interventions in endemic zone. Santé[en notebooks lign off];4:115-17.

8. Xie NJ, Luo SY, Xue L, Li W, Gu MIN., Liu OF IT, Huang WH, Fan RX, Hen JY, Luo JF. (2015): Prophylactic antibiotics: does have necessity in totally percutaneous thoracic endovascular aortic repair? Nan Fang Yi Ke Da XueXueBao.; 35(4):578-82.

9. Moreira AD, Vogel JD, Kalady MF. (2008): Fever assessments after colorectal surgery: identification of risk factors that increase yield and decrease cost. Say Colonist Rectum.; 51:508.
10. Altemeir WA, Culbertson WR, Hummel PR. (1968): Surgical consideration of infections-sources endogenous, types, and methods of control. On Wink North Am.; 48(1):227-40.

11. Ntakiyiruta BLVD, Mugisa SG, Watya. (2006): Early Outcome of Postoperative Pyrexia Following Regimental adjutant Surgery in Mulago Hospital. East and Central African Newspaper Surgery.;11(2):61-65

12. Athanassious C, Samad TO, Avery TO, Cohen J, Chalnick D (2011): Assessment of fever in the immediate postoperative period in patient who total underwent joins arthroplasty - J Arthroplasty (26)8 :1404-1408

13. Longombe TO, Ukumu V. (1989): Malaria. A permanent and non-negligible risk in case of surgery in tropical environment. A prospective survey of 177 cases to the Evangelical Medical Center of Nyakunde (DRC). Afr Med Too much; 28:349-53.

14. Uçkay I, Agostinho TO, Stern R, and al. (2011): Occurrence of fever in the first postoperative week does not help to diagnose infection in clean orthopaedic surgery. intorthop.; 35(8): 1257-1260.

15. Than P, Málovics I. (2000): Significance of postoperative fever after hip prosthesis implantation. $Z$ OrthopIhreGrenzgeb.; 38:430-435. doi: 10.1055/s-200010173.

16. FadlAlla HAS, Fahal AH, Ahmed ME, Hassan MY. (1996): Pattern of postoperative pyrexia Khartoum in. East Afr Med J.; 73(1): 2

17. Fanning J, Brewer J. (2002): Delay of hospital discharge secondary to postoperative fever-is it necessary? $\mathrm{J} \mathrm{Am}$ Osteopath Assoc; 102 (12):660-1

18. Sikora C, Embil J. (2004): Fever in the post-operative Patient: In Chilling Problem. The Canadian Newspaper CME of [on line]., 94-98.

19. Tai TW, Chang CW, Linen CJ, Lay KA, Yang CY. (2009): Elevated temperature trends after total knee arthroplasty. Orthopedics.; 32:886.

\section{How to cite this article:}

MaoneoAzabali et al.2017, Immediate Fever After Clean operations (Class I of Altemeier) In The Northeast of The Democratic Republic of Thecongo (Drc): Etiologic And Therapeutic Aspects. Int J Recent Sci Res. 8(5), pp. 16829-16832.

DOI: http://dx.doi.org/10.24327/ijrsr.2017.0805. 0224 